in a quarter of a mile of it, and all of whom are ready to take any of the districts at the very lowest price that will afford them something approaching to a remuneration; indeed they tendered last year a sum much below what they considered a fair price, but which was rejected by the economical board, who appointed the present person, by which they actually saved the enormous sum of nearly $£ 10$. This appointment has given much disgust to the more liberal part of the neighbourhood, as the poor have been deprived of the attendance of the practitioners to whom they have been accustomed for years, and to whom they are greatly attached, and given over to one of whom they know nothing; and when to this is added the fact of his living at so great a diste nce, and their inability (for want of means) to send for him in cases of emergency, the climax is complete.

The board have now published in the "Plymouth Herald" the terms they mean to give for the ensuing year, which is a copy of the last, except that they will in no case give more than 10s. 6d. for each case of midwifery. How long, Mr. Editor, is such a disgraceful system to last? I have the honour to be yours,

Plympton, Devon,

$$
\text { S. H. Pode, Surgeon. }
$$

March, 1838.

\section{PETITION FROM YORK.}

\section{To the Editor of THe LANCET.}

Srr:-The following is a copy of a petition which has been sent to Lord Dundas, to be presented to the House of Lords, and a similar one to J. H. Lowther, Fsq., for presentation to the House of Commons.

The petitioners include every medical practitioner but one residing in, or in the suburbs of, the city of York. I have the honour to be your obedient servant,

\section{WILliaM A XDERSON, Hon. Sec,}

York, April 28, 1838.

To the Right Honourable the Lords Spiritual and Temporal, in Parliament assembled:

The Petition of the undersigned Medical Practitioners residing in York :

\section{Humbly Showeth,}

That it is notorious that many persons who have received no medical education whatever, and who have not submitted to the examinations required by the existing laws, are now practising the several branches of the medical profession in England and Wales.

That in consequence of the ignorant administration of medicines and unskilful per. formance of surgical and obstetrical opera. tions by such persons, the lives and health of her Majesty's subjects are greatly en. dangered, whilst the regular practitioner, who has duly prepared himself for the responsibilities of practice, by an arduous and expensive course of study, and has proved his fitness by undergoing the strict examinations required by law, is exposed to an illegal, unfair, and most injurious com. petition.

That the only redress now open to the qualified practitioner, and the ouly protec. tion afforded to the public against unqua. lified and ignorant pretenders to medical knowledge, consists in a recourse to the costly, tardy, and, as experience has proved, ineffectual provisions of the existing $A \mathrm{p} 0$. theraries' Act.

Your petitioners therefore pray that your right honourable House would be pleased to institute such inquiry into the evil com. plained of as may enable it in its wisdom to apply thereto such legislative remedy as may effectually secure the public from the dangers of ignorant and empirical practice, and may protect the duly qualified medical practitioner in the exercise of his profes. sion.

And your petitioners will ever pray, \&.

Baldw. Wake, M.D., Physician to the York Lunatic Asy. lum.

Jas. Atkinson, senior surgeon, ditto.

William Stephenson Clarke, surgeon.

W. V. Hope, surg.

J. Hopps, surgeon.

B. Dodsworth, surg.

G. Goldie, M.D.

G. Brown, surgeon.

$O$. Allen, surgeon.

A. Conates, surgeon.

W. Anderson, surg.

H. S. Belcombe, Senior Physician to the York County Hospital

J. T. Dolman, surg.

T. R. Wisker, surg.

F. Swineard, surg.

T. H. Barker, surg.

J. Allen, surgeon.

R. R. Alderson, surg.

W. Dalla Husband, surgeon.

E. Wallis, surgeon.
W. Coates, surgeon.

G. Clark, surgenn.

W. H. Rawdon, M.D.

C. Williams, surro.

R. Hey, surgeon.

H. Crummack, surg.

T. Simpson, M.D., Physician to the York County Hos. pital.

H. Russell, Surgeon to the York County Hospital.

E. T. Allen, surg.

H. Gibson, surgeon.

T. Laycock, HouseSurgeon and Apo. thecary to the York County Hospital.

T. Abbey, surgeon.

T. K. Walker, surg.

J. Wilson, Apothe cary to the York City Dispensary.

W. Matterson, jun. surgeon.

W. Matterson, surg. J.P. Needham, surg J.S. Overton, surg. 